\title{
Retraction Note to: Adsorptive removal of cadmium from aqueous media using Posidonia oceanica biomass: equilibrium, dynamic and thermodynamic studies
}

\author{
F. Krika ${ }^{1} \cdot$ N. Azzouz ${ }^{1,2} \cdot$ M. C. Ncibi ${ }^{2}$
}

Published online: 15 January 2018

๑ Islamic Azad University (IAU) 2017

\section{Retraction Note to: Int. J. Environ. Sci. Technol. (2015) 12:983-994 DOI 10.1007/ s13762-013-0483-x}

The authors are retracting this article (Krika et al., 2015) because Figure $2 \mathrm{C}$ and the text describing it are duplicated from a previously published article by Allouche et al. (2011). All authors agree to this retraction.

\section{References}

Allouche F-N, Mameri N, Guibala E (2011) Pb(II) biosorption on Posidonia oceanica biomass. Chem Eng J 168:1174-1184

Krika, F Azzouz N, Ncibi MC (2015) Adsorptive removal of cadmium from aqueous media using Posidonia oceanica biomass: equilibrium, dynamic and thermodynamic studies. Int J Environ Sci Technol 12:983-994
The online version of the original article can be found under doi:10.1007/s 13762-013-0483-x.

\section{F. Krika}

base200974@yahoo.fr

1 Department of Process Engineering, University of Laghouat, BP 37G, Laghouat 03000, Algeria

2 COVACHIM Laboratory, University of Antilles and Guyane, BP 250, 97157 Pointe à Pitre Cedex, France 